\title{
Hearing Protection Evaluation for the Combat Arms Earplug at Idaho National Laboratory
}

\author{
James Lovejoy
}

March 2007

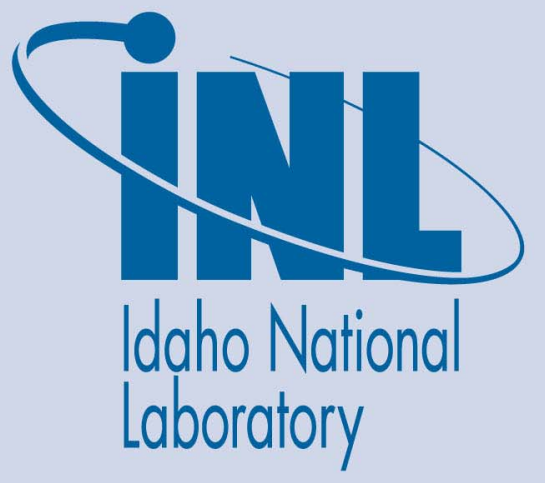

The INL is a U.S. Department of Energy National Laboratory operated by Battelle Energy Alliance 


\section{Hearing Protection Evaluation for the Combat Arms Earplug at Idaho National Laboratory}

James Lovejoy

March 2007

Idaho National Laboratory

Idaho Falls, Idaho 83415

Prepared for the

U.S. Department of Energy

Office of Nuclear Energy

Under DOE Idaho Operations Office

Contract DE-AC07-05ID14517 


\section{EXECUTIVE SUMMARY}

The Idaho National Laboratory (INL) is managed by Battelle Energy Alliance, LLC (BEA) for the Department of Energy. The INL Protective Security Forces (Pro Force) are involved in training exercises that generate impulse noise by small arms fire. Force-on-force (FOF) training exercises that simulate real world scenarios require the Pro Force to engage the opposition force (OPFOR) while maintaining situational awareness through verbal communications.

The Combat Arms ${ }^{1}$ earplug was studied to determine if it provides adequate hearing protection in accordance with the requirements of MIL-STD-1474C/D. The Combat Arms earplug uses a design that allows continuous noise through a critical orifice while effectively attenuating high-energy impulse noise. The earplug attenuates noise on a non-linear scale, as the sound increases the attenuation increases. The INL studied the effectiveness of the Combat Arms earplug with a Bruel \& Kjaer (B\&K) head and torso simulator used with a selection of small arms to create impulse sound pressures. The Combat Arms earplugs were inserted into the B\&K head and torso ears, and small arms were then discharged to generate the impulse noise.

The INL analysis of the data indicates that the Combat Arms earplug does provide adequate protection, in accordance with MIL-STD-1474C/D, when used to protect against impulse noise generated by small arms fire using blank ammunition. Impulse noise generated by small arms fire ranged from 135-160 $\mathrm{dB}$ range unfiltered un-weighted. The Combat Arms earplug attenuated the sound pressure 10-25 dB depending on the impulse noise pressure. This assessment is consistent with the results of previously published studies on the Combat Arms earplug (see Section 5, "References"). Based upon these result, the INL intends to use the Combat Arms earplug for FOF training exercises.

\footnotetext{
${ }^{1}$ References herein to any specific commercial product, process, or service by trade name, trademark, manufacturer, or otherwise, does not necessarily constitute or imply its endorsement, recommendation, or favoring by the U.S. Government, any agency thereof, or any company affiliated with the Idaho National Laboratory.
} 


\section{CONTENTS}

EXECUTIVE SUMMARY

1. INTRODUCTION 1

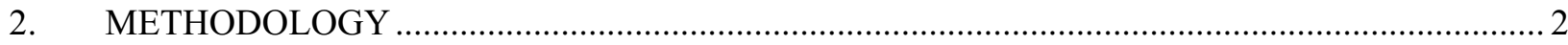

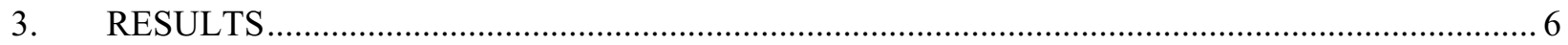

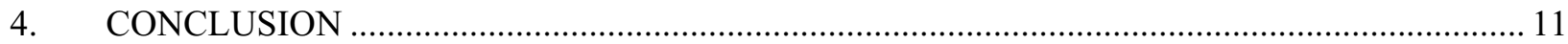

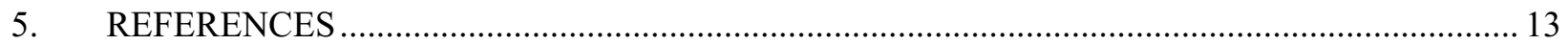

\section{FIGURES}

1. An illustration of how the unprotected ear, the Combat Arms earplug, and the foam earplug

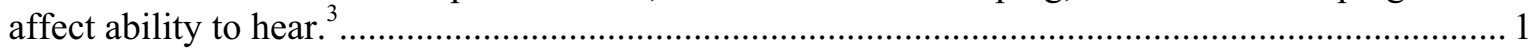

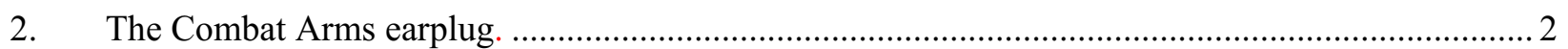

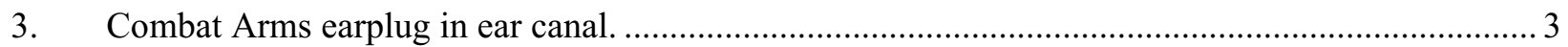

4. Performance of hearing protectors in impulse noise, French-German Research Institute study.

5. Non-linear attenuation curve measuring insertion loss versus frequency (U.S. Center for Health Promotion and Preventive Medicine).

TABLES

1. Acoustical print of an impulse noise generated by a firearm's very sharp rise followed by a slower drop off.

2. MIL-STD-1474D impulse noise exposure daily limits. .......................................................... 4

3. MIL-STD-1474D impulse noise exposure daily limits. ......................................................... 5

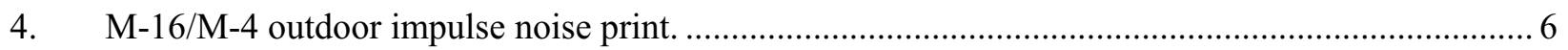

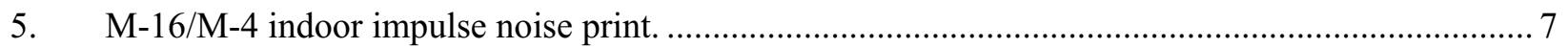

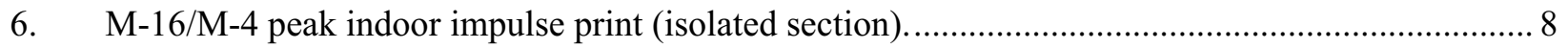

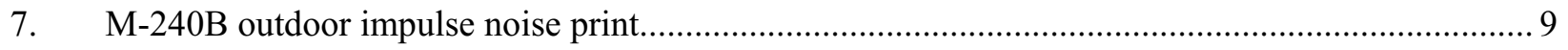

8. M-240B machine gun impulse indoor impulse noise print. ….................................................... 9

9. LAW impulse noise graph plot (isolated section). .................................................................. 10 


\section{ACRONYMS}

ACGIH American Conference of Governmental Industrial Hygienists

ANSI American National Standards Institute

DOD Department of Defense

FOF force-on-force

INL Idaho National Laboratory

ISO International Standards Organization

LAW Light Anti Tank Weapon

OPFOR Opposition Forces

Pro Force Protective Security Forces

SPO Pro Force officers

TLV Threshold Limit Values 


\section{Hearing Protection Evaluation for the Combat Arms Earplug at Idaho National Laboratory}

\section{INTRODUCTION}

The INL Protective Security Forces (Pro Force) are involved in training exercises that generate impulse noise (blast overpressure) by small arms fire. Force-on-force (FOF) training exercises that simulate real world scenarios require the Pro Force to engage the opposition force (OPFOR) while maintaining situational awareness through verbal communications. FOF exercises expose Pro Force officers to impulse noise levels exceeding MIL-STD-1474C/D limits. The Combat Arms earplug (see Figure 1) is currently used by the U.S. military to protect soldiers from excessive noise exposure while allowing for adequate verbal communication between first line leaders and soldiers in a combat environment. The INL Safeguards and Security organization studied the Combat Arms earplug to determine if attenuation levels of the earplug provide necessary compliance to MIL-STD-1474C/D limits for INL protective security forces activities.

Previous studies have been conducted on the Combat Arms earplug. These studies were sponsored by the Department of Defense (DOD) (see Section 5 "References") and the French-German Research Institute. The INL evaluation of the Combat Arms earplug used similar methodologies for the basis of this study. The INL study was performed in order to provide further evidence of the adequacy of the Combat Arms earplug and its effectiveness relative to conditions at the INL.

Figure 1, referenced in the DOD study, illustrates the benefit of using the Combat Arms earplug during FOF exercises and distinct sounds identified at listed distances. The detection model developed at the DOD Army Research Laboratory predicts a normal-hearing soldier can detect a truck at the same distance ( 800 meters) with or without the non-linear earplug. The detection capability is cut in half (400 meters) with conventional foam plugs.

\section{DETECTION OF SOUND BY}

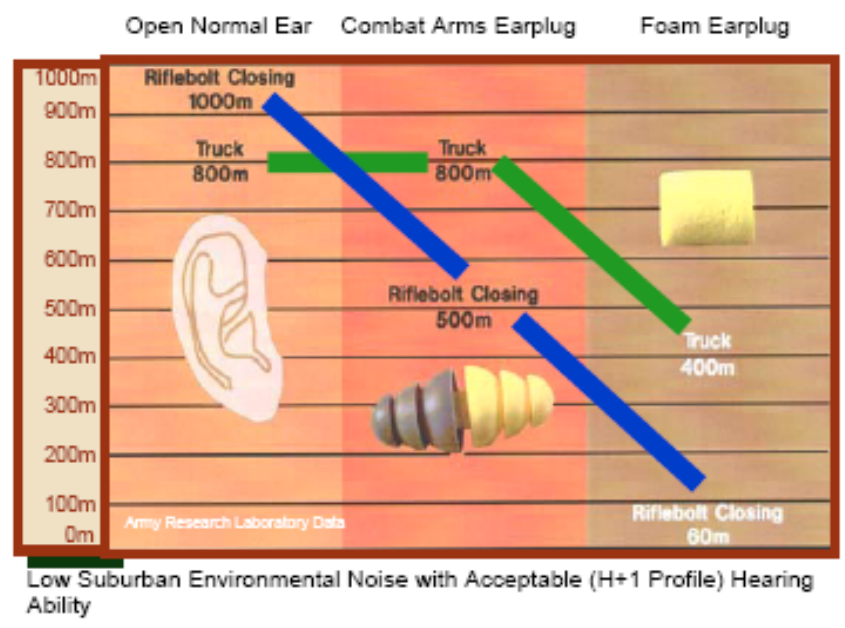

Figure 1. An illustration of how the unprotected ear, the Combat Arms earplug, and the foam earplug affect ability to hear. ${ }^{3}$ 


\section{METHODOLOGY}

The data for this study was collected using B\&K Pulse Version 11 software with the B\&K Pulse sound and vibration hardware and $B \& K$ artificial head and torso with simulated ears. The INL used the B\&K head and torso simulator based on the ability to determine effective impulse noise attenuation of the Combat Arms earplug without exposing human subjects to impulse noise for research. This method evaluates the Combat Arms earplug using objective data by capturing insertion loss of the earplug.

It is recognized that the $\mathrm{B} \& \mathrm{~K}$ head and torso simulator, off the shelf, does not meet the criteria for the International Standard Organization (ISO) or the American National Standards Institute (ANSI) standards on low frequency noise measurements. In humans, sound pressure is transferred through bones and flesh to the audio receptors in the ear. The B\&K head does not transfer low frequency noise the same way the human head transfers noise. ANSI/ISO methods require additional soundproofing and isolation in the $\mathrm{B} \& \mathrm{~K}$ head to meet the standards. Because of these differences, the actual transmission of impulse noise can be presumed to be slightly higher than actual impulses noise levels because the B\&K head and torso used in this study was not modified to meet the ANSI/ISO standard. This results in a conservative estimate of actual exposure transmission.

The design of the Combat Arms earplug, shown in Figure 2, is described as a non-linear earplug that has a precise orifice in the plug that allows continuous noise to enter and transmit into the ear canal. Impulse noise is attenuated by the precise dimensions of the orifice in the earplug. Figure 3 demonstrates placement of the yellow insertion end of the earplug into the ear canal. The yellow end contains the orifice providing "hear-through" protection while the green end provides a conventional closed earplug with a constant NRR of $22 \mathrm{~dB}$.
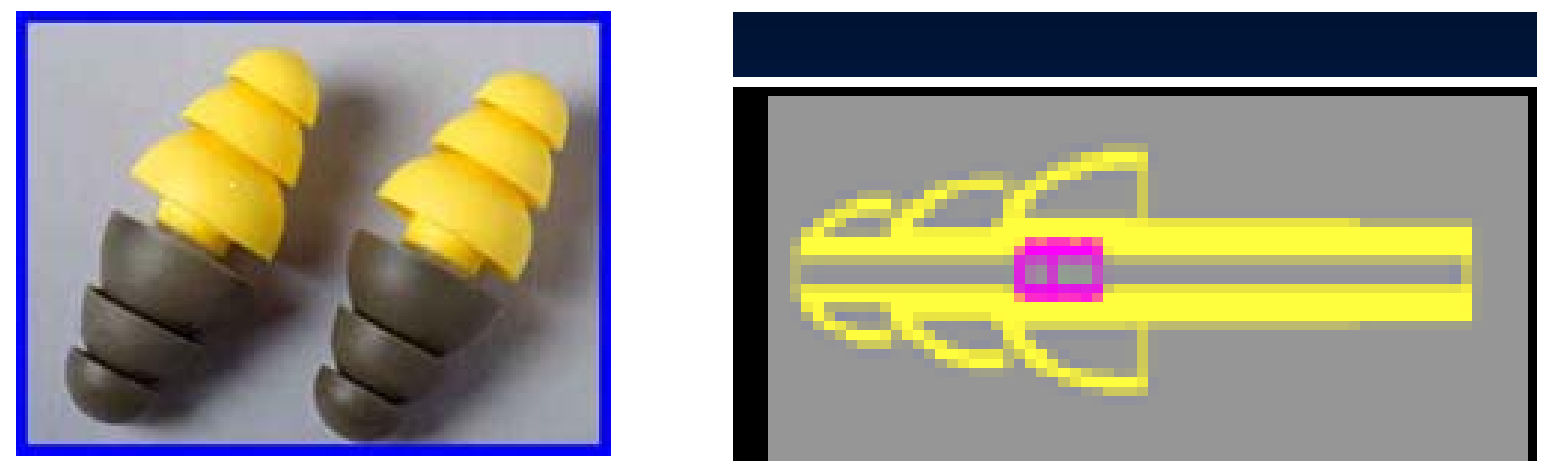

Figure 2. The Combat Arms earplug. 


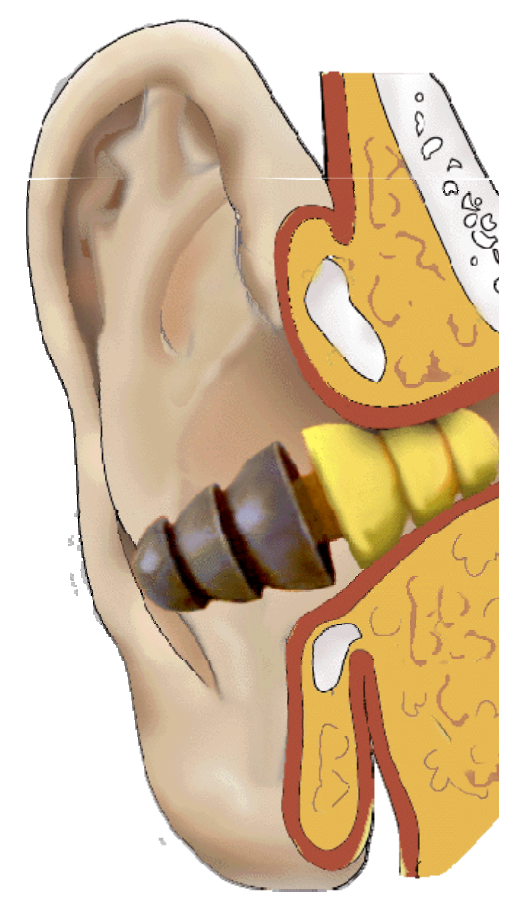

Figure 3. Combat Arms earplug in ear canal.

Impulse noise, generated from small arms fire at the INL, is a short burst of an acoustic energy consisting of either a single impulse or a series of impulses, as shown in Table 1. The pressure time history of a single impulse includes a rapid rise to a peak pressure, followed by a slower decay of the pressure to ambient pressure, occurring in less than 1 second.

Table 1. Acoustical print of an impulse noise generated by a firearm's very sharp rise followed by a slower drop off.

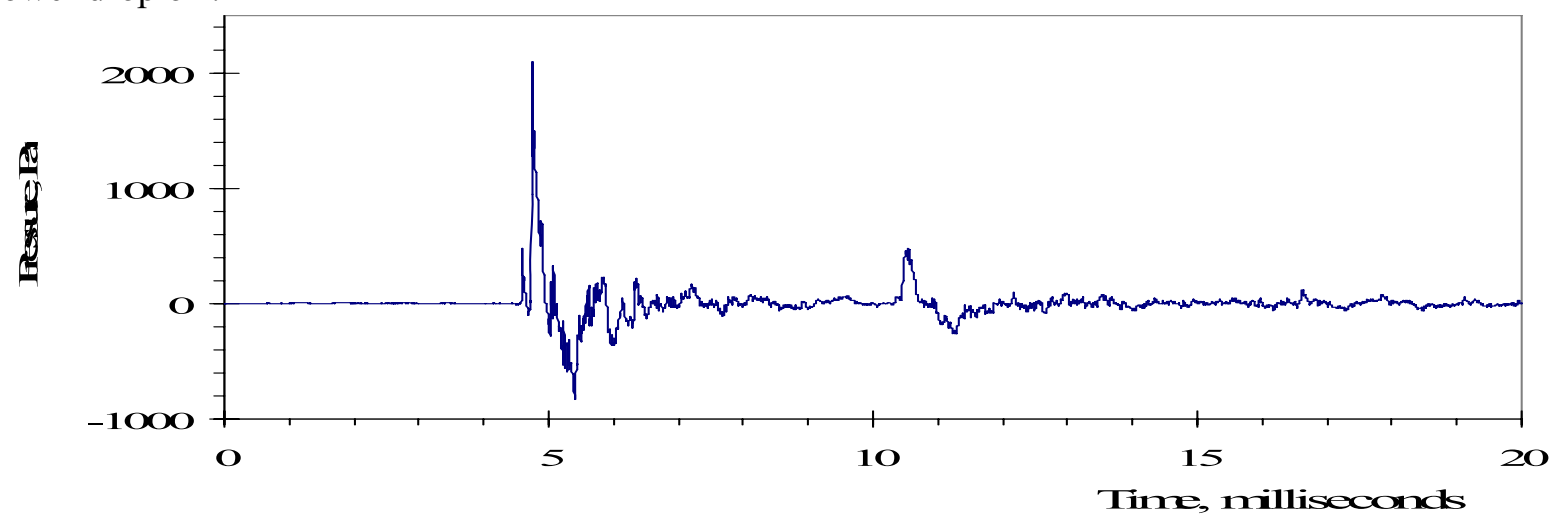

Impulse noise passes through the precise orifice of the Combat Arms earplug and creates acoustic friction, which attenuates the sound pressure. This noise reduction capability increases with the noise level. The non-linearity attenuation begins at $110 \mathrm{~dB}$ and increases to $190 \mathrm{~dB}$ with an overall peak reduction of $25 \mathrm{~dB}$. Department of Defense noise limits established in MIL-STD-1474C/D regulate Cweighted impulse sound pressure above $140 \mathrm{~dB}$, as referenced in the ACGIH TLV booklet. Exposures over $140 \mathrm{~dB}$ require the use of hearing protection providing adequate impulse noise attenuation. 
The number of allowable unprotected sound pressure impulses is limited by MIL-STD-1474D based on sound pressure and impulse duration as shown in Table 2. Table 3 illustrates the maximum allowable exposures as the impulse noise increases in duration, pressure, or both. MIL-STD-1474D states, "The initial requirement is that impulse noise shall not exceed the limits specified for limit W in order to meet the hearing conservation criterion for unprotected ears. Limits X, Y, or Z, for which hearing protection is mandatory, shall be selected only if it can be clearly documented that meeting limit $\mathrm{W}$ is beyond the state-of-the-art, the cost of reducing the noise level to that specified for limit $\mathrm{W}$ is prohibitive, or that system effectiveness will be seriously degraded by reducing the noise level to that specified for limit W. Limits X, Y, or Z shall be selected only with the approval of the procuring activity subject to reduction of the level to the impulse noise levels above limit W (i.e., anything greater than 140 $\mathrm{dB}$ ) require the use of hearing protectors for any number of exposures per day."1

Table 2. MIL-STD-1474D impulse noise exposure daily limits.

\begin{tabular}{|c|c|c|c|c|}
\hline \multirow{2}{*}{\multicolumn{2}{|c|}{ Impulse Noise Limit }} & \multicolumn{3}{|c|}{ Maximum Permissible Number $(\mathrm{N})$ of Exposures/Day ${ }^{1}$} \\
\hline & & No Protection & Either Plugs or Muffs & Both Plugs and Muffs \\
\hline & $\mathrm{W}$ & 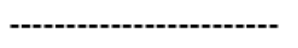 & Unlimited Exposure & - \\
\hline & $\mathrm{X}$ & 0 & 2000 & 40000 \\
\hline & $\mathrm{Y}$ & 0 & 100 & 2000 \\
\hline & Z & 0 & 5 & 100 \\
\hline \multicolumn{5}{|c|}{$\begin{array}{l}{ }^{1} \text { A single exposure consists of either (a) a single impulse for non-repetitive systems } \\
\text { (systems producing not more than one impulse per second, e.g., rocket launchers fired from } \\
\text { the shoulder), or (b) a burst for repetitive systems (systems normally producing more than } \\
\text { one } \\
\text { impulse per second, e.g., automatic weapons (see 5.4.2.)). The equation for calculating the } \\
\text { allowable number of exposures per day is: }\end{array}$} \\
\hline \multicolumn{5}{|c|}{$\begin{array}{l}\mathrm{N}_{1}=10^{\mathrm{x}} \text { where } \mathrm{x}=\frac{1}{5}\left[177-\mathrm{L}+6.64 \log _{10} \frac{200}{\mathrm{~T}}\right] \\
\mathrm{N}_{2}=20 \mathrm{XN}_{1}, \text { and }\end{array}$} \\
\hline \multicolumn{5}{|c|}{$\mathrm{N}_{1}=$ allowable number of impulses/day (single protection) } \\
\hline \multicolumn{5}{|c|}{$\mathrm{N}_{2}=$ allowable number of impulses/day (double protection) } \\
\hline \multicolumn{5}{|c|}{$\mathrm{L} \quad=$ measured peak sound pressure level, in $\mathrm{dB}$} \\
\hline \multicolumn{5}{|c|}{$\mathrm{T}=$ measured $\mathrm{B}$-duration in milliseconds } \\
\hline
\end{tabular}


Table 3. MIL-STD-1474D impulse noise exposure daily limits.

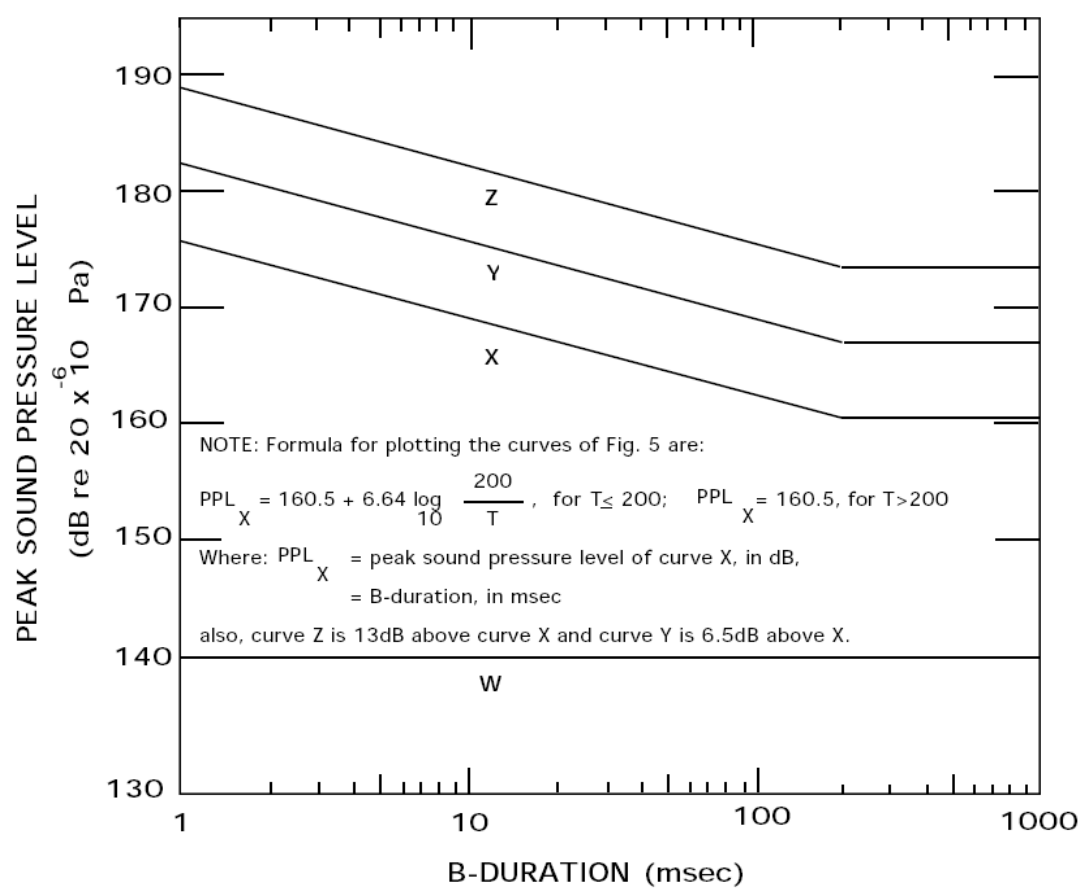

Data was collected both outdoors and indoors using an M-16 A2, M-4 Carbine, M-240B MG, and a Light Anti Tank Weapon (LAW) simulator. Each weapons system was discharged with the B\&K recording the impulse noise. The head and torso were isolated on a tabletop, the weapons systems were held to the shoulder of the torso in proximity to the right ear. It is important to note that the head could not be manipulated to hold a cheek-to-stock sight picture. In human subjects, the ear that is held closest to the stock of the weapon during discharge is protected more than the other ear. The B\&K head and torso ears were exposed equally to the firearm discharge. The B\&K recorded peak impulses unfiltered and unweighted.

The M-16A2 and M-4 Carbine were discharged in increments of five rounds each, repeated three times for a total of 15 rounds. Two unprotected microphones were positioned parallel to the weapon and two protected microphones were located in the molded ears. The Combat Arms earplug was inserted in each ear. The M-240B was discharged in increments of three, five round bursts, repeated 12 times for a total round count of approximately $40-50$ rounds both indoors and outdoors. The LAW simulator was discharged only outdoors and using a total of four rounds. Outdoor tests were performed away from buildings with the $\mathrm{B} \& \mathrm{~K}$ head and torso on a standard tabletop, therefore isolated from any effects that the ground would have on the impulse noise data. The M-240B was discharged in bursts of fire expending a belt of $45-50$ rounds. 


\section{RESULTS}

The INL data collected by the B\&K head and torso is presented in Tables 4-7. Each impulse print illustrates a sharp rise to a peak level and a slower downside to background level. Each peak represents a single firearm discharge. Each graph represents the respective weapons system. Each recording compiled approximately 10,000 data points measured in milliseconds.

The impulse noise prints compare the sound pressure versus the duration in milliseconds for each of the microphones. Table 4 is the impulse noise print of the M-16/M-4 rifle. The first five peaks in the graph are single discharges from a weapon dedicated for firing blanks only. By porting and plugging the barrel, it eliminated the need for a military blank adapter. Table 5 is the same weapon discharged indoors to allow for the influence of acoustically reflective surfaces in the analysis. Table 6 is a single impulse print of the indoor test. The reflective properties of the building account for the increased sound pressure levels between Table 4 and 5.

Tables 5, and 6 shows four distinct data plots: right and left ears without the Combat Arms earplug and right and left ears with the Combat Arms earplug. The highest impulse peak on Table 5 represents the unprotected exposure to the M-16/M-4, between 143-146 dB. The Combat Arms earplug attenuated the impulse noise 7-10 dB, resulting in protected exposures below the $140 \mathrm{~dB}$ limit. The allowable exposure for single hearing protection at levels above $140 \mathrm{~dB}$ is 2000 impulses per day (see Table 2). Table 4 shows the peak impulse noise for the M-16/M-4 discharged outdoors is below the $140 \mathrm{~dB}$ limit requiring hearing protection.

The difference between the impulse noise levels indoors versus outdoors is approximately $14 \mathrm{~dB}$. Table 5 is the impulse noise recording for the M-16/M-4 recorded inside a tall open vehicle bay with little or no sound absorbing material. The roll up door to the bay was closed with the vehicles removed. The highest potential for exposure to impulse noise is when the weapon is discharged indoors.

Table 4. M-16/M-4 outdoor impulse noise print.

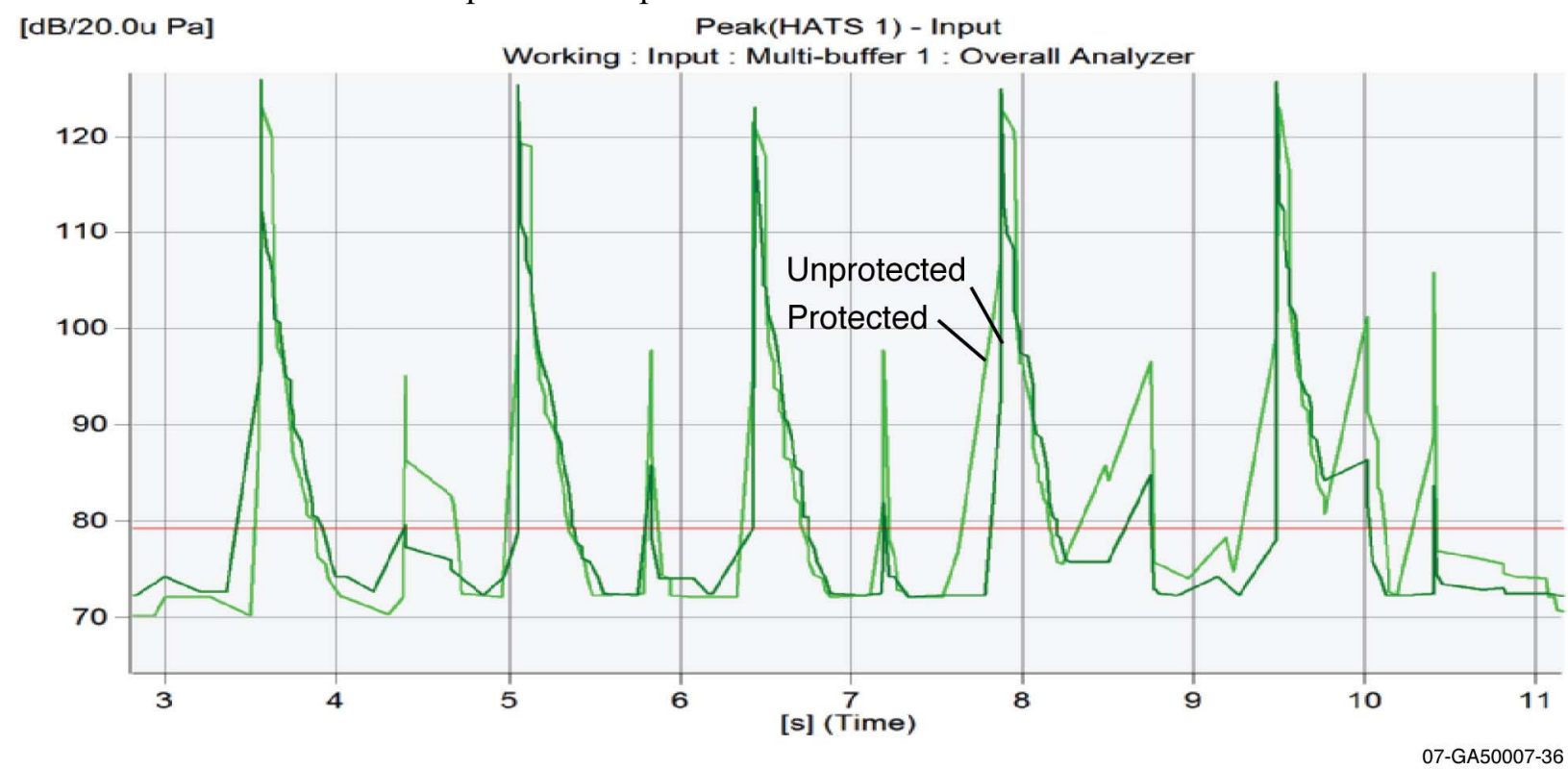


Table 5. M-16/M-4 indoor impulse noise print. [dB/20.0u Pa]

Peak(HATS 1) - Input

Working : Input : Multi-buffer 1 : Overall Analyzer

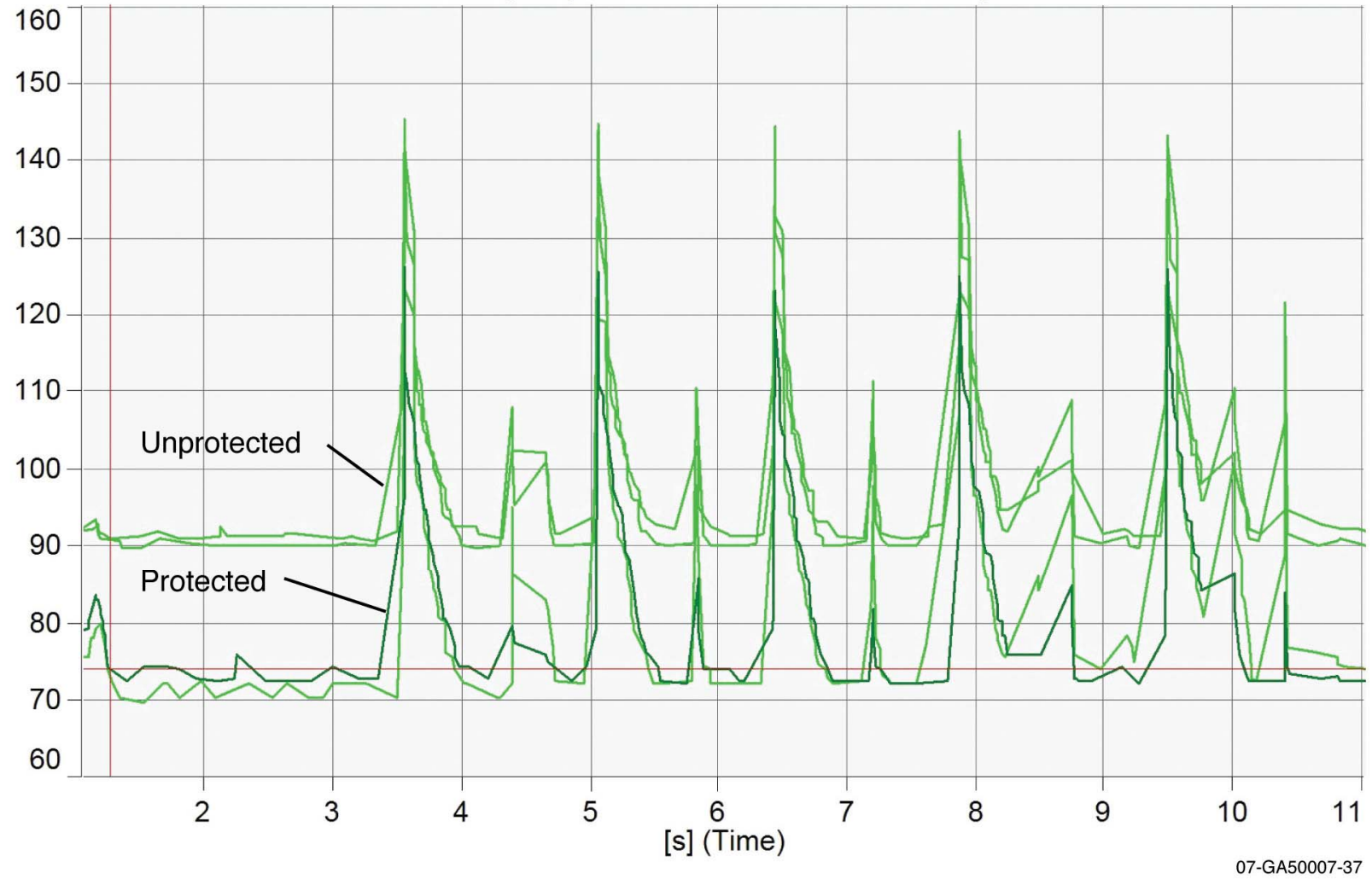


Table 6 is a single M-16/M-4 peak indoor impulse noise print. The impulse noise print shows the attenuation of the Combat Arms earplug. The data demonstrates that the non-linear earplug provides attenuation of impulse noise.

Table 6. M-16/M-4 peak indoor impulse print (isolated section).

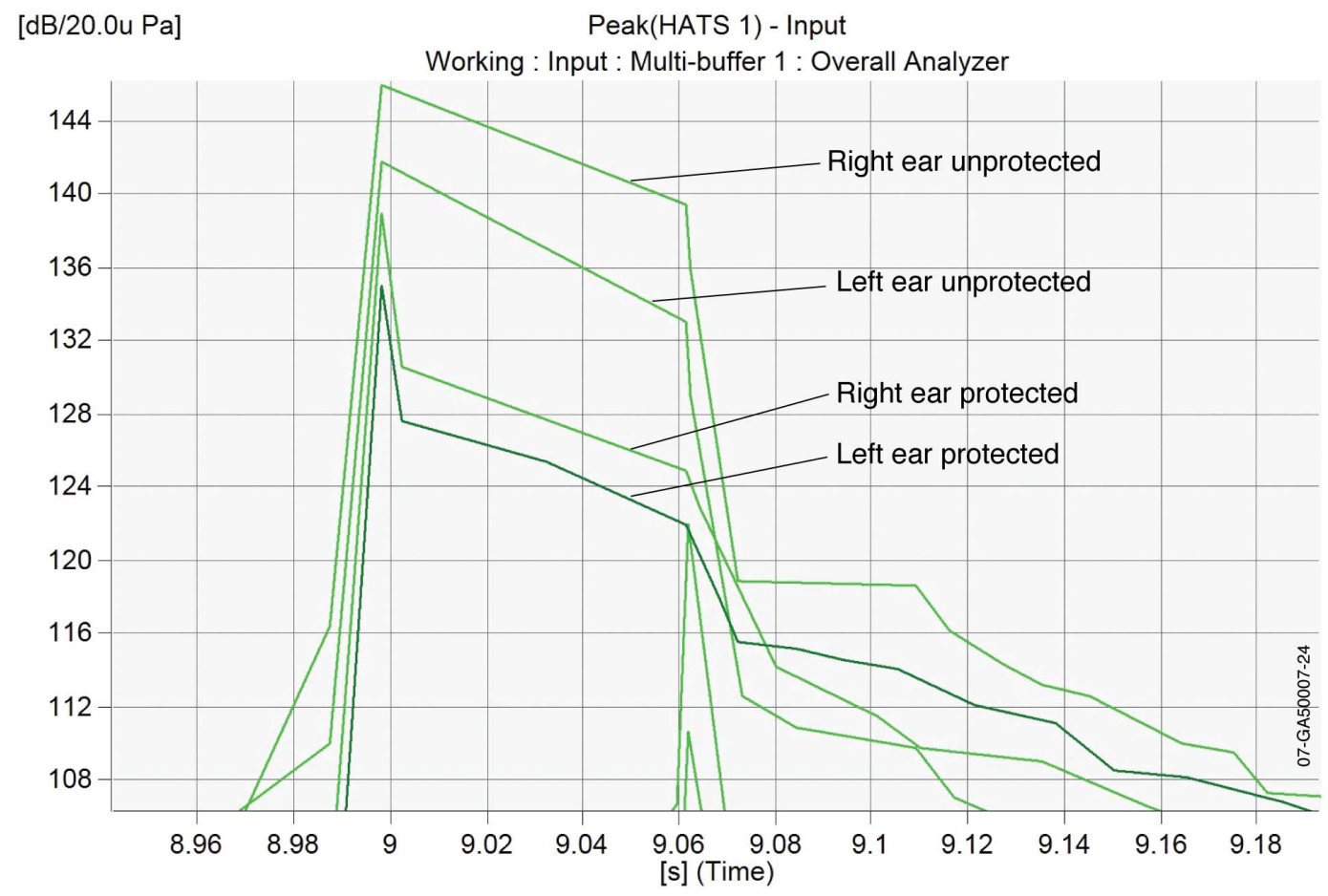

Table 7 is the impulse noise print recorded outdoors with the $\mathrm{B} \& \mathrm{~K}$ head and torso on a tabletop. Table 8 is the impulse noise print recorded indoors. The impulse noise indoors is almost $160 \mathrm{~dB}$. The Combat Arms earplug attenuated the sound pressure to approximately $142 \mathrm{~dB}$ in the right protected ear and $132 \mathrm{~dB}$ in the protected left ear. The delta between the two ears represents the distance the sound travels and the curvature of the head. The non-linearity of the earplug attenuation increases as the sound pressure increases.

The M-240B weapon is designed with a bi-pod and is belt fed. The weapon can be fired from a standing position, however the likely scenario is that it will be used in a prone position close the ground or a barrier which will influence the impulse noise print of the weapon. The M-240 is a loud weapon system with a distinct sound. The weapon sound pressure delta between indoors and outdoors ranges between 10 and $15 \mathrm{~dB}$. This weapon has a high cyclic rate of fire and high sound pressure. The attenuation of the Combat Arms earplug reduces the impulse noise on the predicted non-linear scale. 
Table 7. M-240B outdoor impulse noise print.

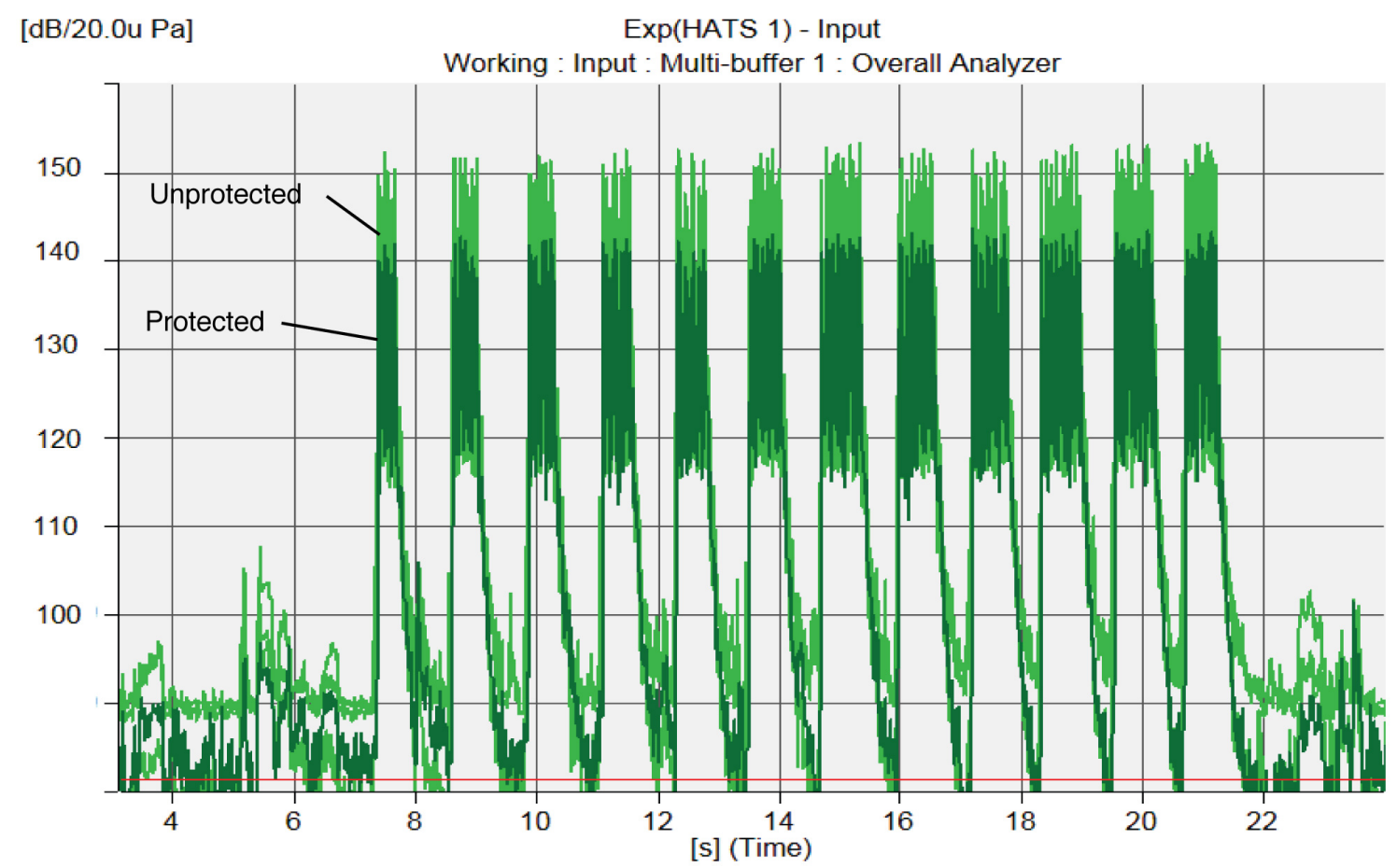

07-GA50007-38

Table 8. M-240B machine gun impulse indoor impulse noise print.

[dB/20.0u Pa] Peak(HATS 1) - Input

Working : Input : Multi-buffer 1 : Overall Analyzer

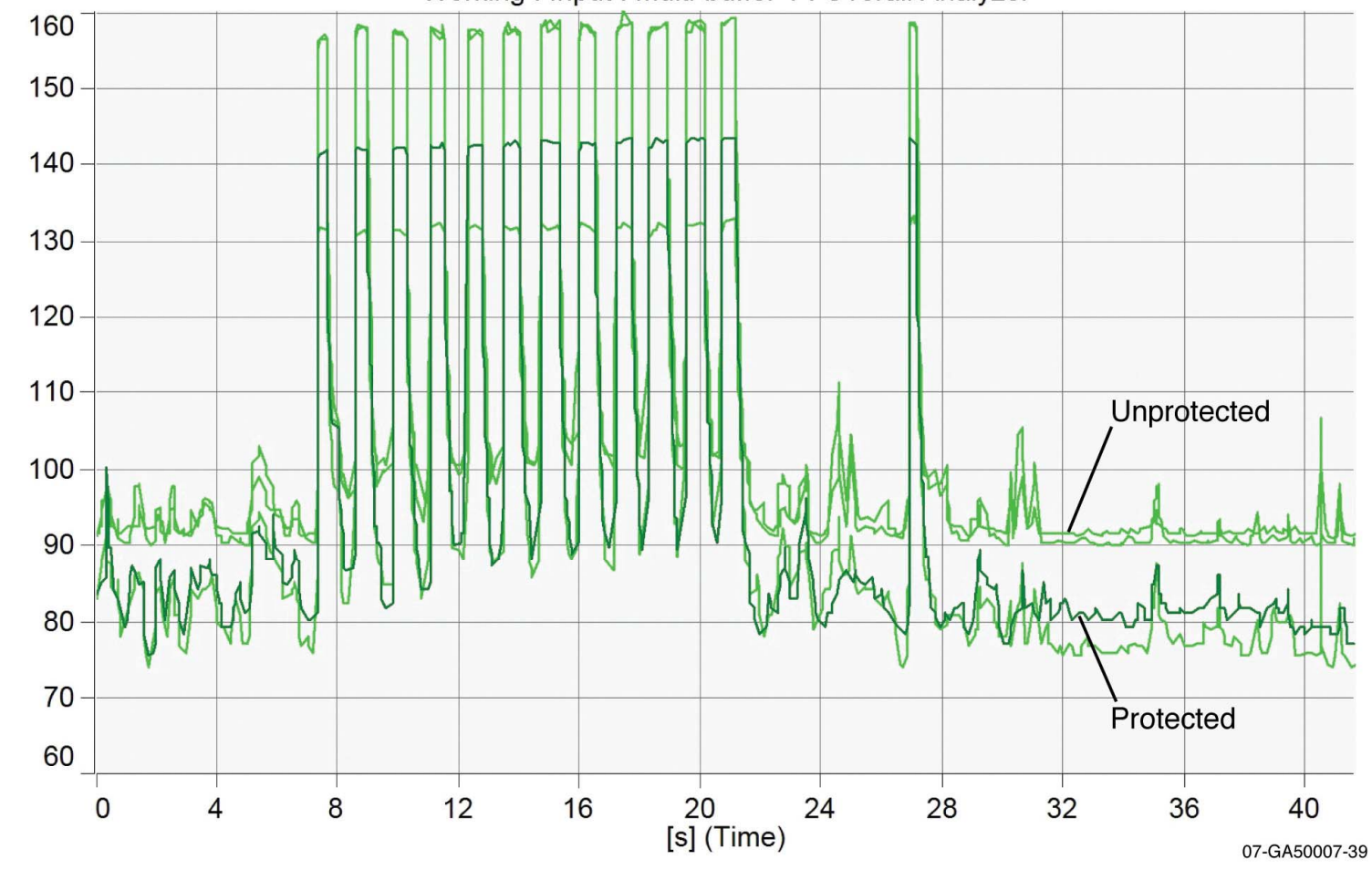


Table 9 is the impulse noise print for the LAW rocket simulator. The peak is very sharp with a quick drop off. The LAW rocket simulator is not a weapon system that is fired indoors during FOF exercises. The impulse noise is attenuated from an unprotected $155 \mathrm{~dB}$ to approximately $141 \mathrm{~dB}$ protected. The graph represents outdoor measurements for a single ear in order to show the detail of the impulse print.

Table 9. LAW outdoor impulse noise graph plot (isolated section).

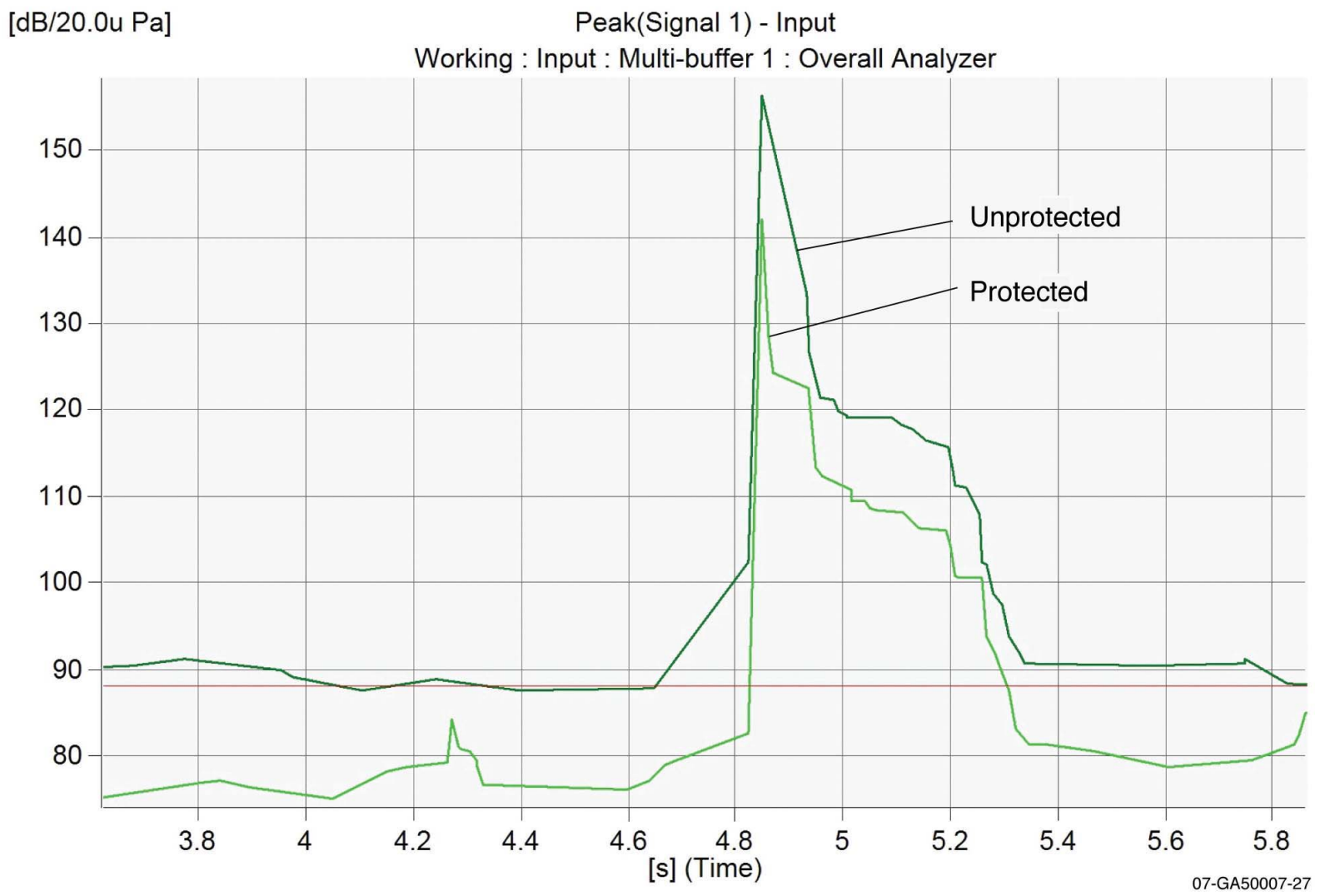




\section{CONCLUSION}

The objective data measured in this study using the B\&K head and torso simulator correlates directly with previous studies performed by the French-German Research Institute and U.S. Army Center for Health Promotion and Preventive Medicine using the Combat Arms earplug. Figures 4 and 5 from these studies also illustrate that at respective frequencies and sound pressures, non-linear attenuation is achieved.

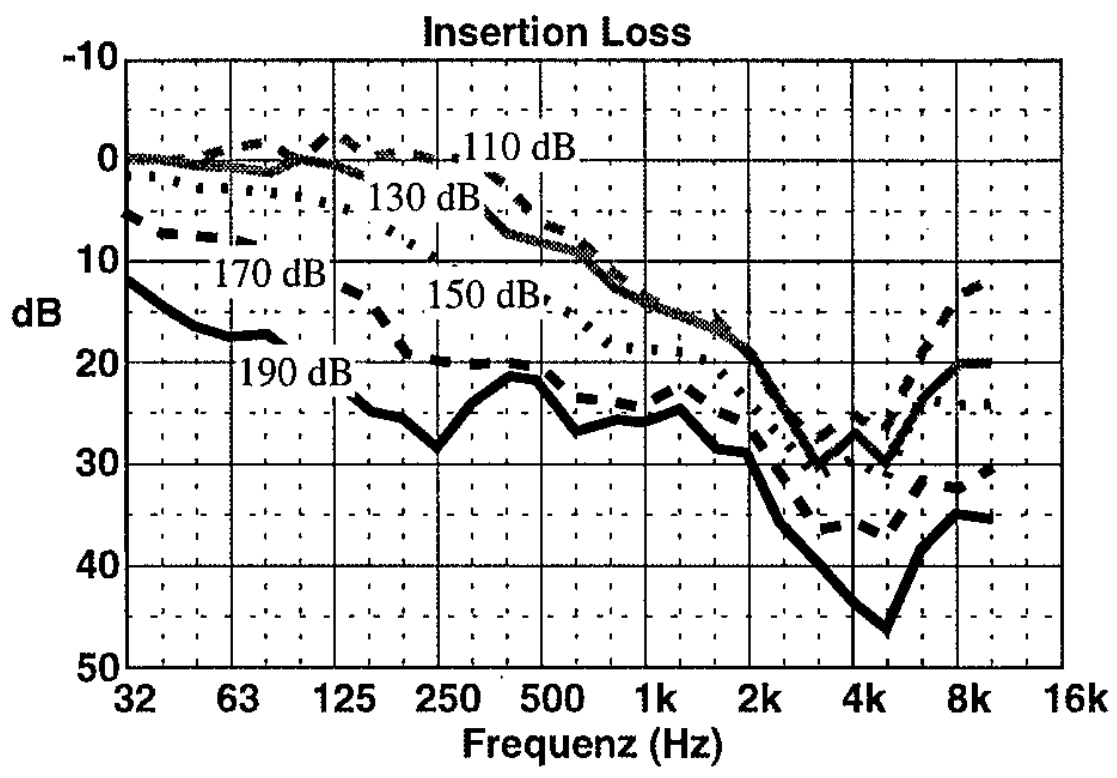

Figure 4. Performance of hearing protectors in impulse noise, French-German Research Institute study.

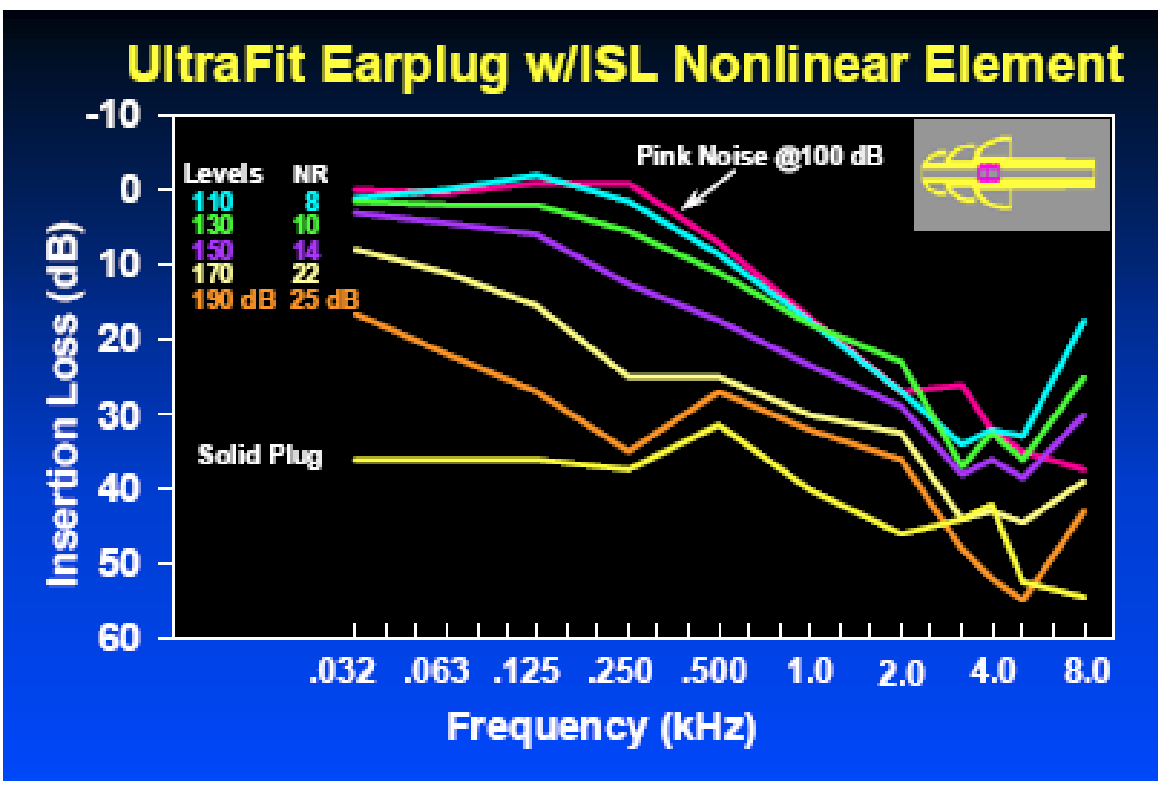

Figure 5. Non-linear attenuation curve measuring insertion loss versus frequency (U.S. Center for Health Promotion and Preventive Medicine). 
The INL study of the Combat Arms earplug concluded that non-linear attenuation of impulse noise levels, using the Combat Arms earplug, provides adequate protection for INL Pro Force officers (SPOs) while allowing necessary verbal communications during FOF exercises. Impulse noise is significantly reduced and most speech energy passes through the critical orifice to the audiometric receptors. Results of the INL study were also consistent with previous studies performed by the French-German Research Institute and U.S. Army Center for Health Promotion and Preventive Medicine.

The Combat Arms earplug provides conservative protection from impulse noise generated by small arms fired in training scenarios. The indoor impulse noise generated by firearms using blanks is above $140 \mathrm{~dB}$ and requires hearing protection in accordance with MIL-STD-1474D. Foam earplugs or standard earmuffs do not allow the SPO to hear effectively, not only enemy activity, but also the coordinating commands or signals from leadership or fellow SPOs during the FOF exercises. Using the Combat Arms earplug on FOF exercises provides a balance between realistic training and employee protection. The results of this study support implementation and use of Combat Arms earplugs during FOF exercises performed at the INL. 


\section{REFERENCES}

1. MIL-STD-1474D, “Department of Defense Design Criteria Standard, Noise Limits," U.S. DOD, Washington DC, February 12, 1997.

2. Buck, K., "Performance of Hearing Protectors in Impulse Noise," French-German Research Institute, June 2000.

3. USACHPPM 51-004-0204, "The Combat Arms Earplug," U.S. Army Center for Health Promotion and Preventive Medicine.

4. American Conference of Governmental Industrial Hygienists, "2006 Threshold Limit Values for Chemical Substances and Physical Agents". 